\title{
Eksekutiv svikt etter hjerneslag
}

BAKGRUNN Eksekutiv svikt innebærer redusert evne til initiering, styring og monitorering av målrettet atferd. Tilstanden forblir ofte udiagnostisert.

KUNNSKAPSGRUNNLAG Denne oversikten er basert på litteratursøk med ordene «stroke» og «executive function» via søkemotoren McMaster Plus og i databasene Cochrane Library og PubMed samt egne erfaringer.

RESULTATER Eksekutiv svikt er en vanlig form for slagrelatert kognitiv dysfunksjon. Den sameksisterer ofte med emosjonell instabilitet og depresjon og er en viktig risikofaktor for tap av selvhjulpenhet og for redusert overlevelse. Diagnostikken er basert på anamnese og observasjon, supplert med kognitive tester. Eksekutiv svikt forekommer også hos personer uten distinkte kliniske hendelser, men med bildediagnostiske tegn på cerebral iskemi, og ved andre hjernesykdommer som Parkinsons sykdom og demenssykdommer. Anatomisk substrat for eksekutiv funksjon er i hovedsak prefrontal cortex og subkortikale baner, men slik svikt ses også ved lesjoner i andre hjerneområder. I behandlingen legges det vekt på kompenserende strategier og gjenvinning av tapt funksjon.

FORTOLKNING Eksekutiv svikt er vanlig ved slagrelatert kognitiv svikt, og tilstanden påvirker prognosen. Det er behov for systematisk testing og strategier for behandling og forebygging.

En 79 år gammel kvinne ble åtte timer etter symptomdebut innlagt i sykehus med nyoppståtte pareser i høyre kroppshalvdel. CTundersøkelse viste ferskt infarkt frontoparietalt på venstre side. Etter to ukers behandling og rehabilitering var de motoriske utfallene betydelig bedret, og kvinnen ble utskrevet til sitt hjem. Hun ble ansett som heldig, ettersom utfallene var moderate og hun hadde kommet seg fint. Tre uker senere kommer hun til fastlegen sammen med datteren, som er fortvilet over morens tilstand. Etter hjemkomsten har hun for det meste sittet $i$ en stol, datteren må hale henne med seg og nærmest kommandere henne. Hun kommer ikke i gang med aktiviteter på egen hånd. Datteren mener moren må være deprimert og lurer på om fastlegen kan gi henne et antidepressivt legemiddel.

Historien er oppdiktet, men pasienten er representativ for dem vi møter i klinisk praksis. Hva er årsaken til at hjerneslagrammede blir sittende initiativløse hjemme, ute av stand til å planlegge og gjennomføre aktiviteter? Skyldes det sensomotorisk skade, manglende motivasjon, depresjon eller manglende evne til initiering og planlegging grunnet eksekutiv svikt?

Eksekutiv funksjon defineres som evnen til uavhengig, målrettet, egennyttig atferd (1). Svikt i slike evner overses ofte i rutinemessig diagnostikk og behandling av slagpasienter. I denne artikkelen drøftes eksekutiv svikt etter hjerneslag, som er en av flere hjernesykdommer som kan gi sviktende eksekutive funksjoner.

\section{Kunnskapsgrunnlag}

Artikkelen er basert på et litteratursøk med ordene «executive function/dysfunction» og «stroke» via søkemotoren McMaster Plus og i databasene Cochrane Library og PubMed. Det ble gjort separate søk på «executive function» for å avklare begrepet.

Større randomiserte studier og oversiktsartikler er vektlagt. I tillegg er referanselistene fra artiklene brukt for å finne mer litteratur enn det som fremkom ved egne søk. Funn fra litteraturen er supplert med egne erfaringer.

\section{Eksekutiv funksjon - begrepsavklaring}

«Eksekutive funksjoner» er en samlebetegnelse på kognitive prosesser som gjør en person i stand til å generere ideer, planlegge, initiere handlinger, tilpasse seg nye eller uvante situasjoner, sortere sanseinntrykk, konsentrere seg, være utholdende, vise kognitiv fleksibilitet, forholde seg simultant til flere kognitive prosesser og undertrykke uønskede responser (2). Eksekutiv funksjon er en forutsetning for å mestre målrettet atferd (2), løse komplekse oppgaver, modifisere atferden i lys av ny informasjon, generere strategier og utføre handlinger på en planlagt og hensiktsmessig måte (3). Eksekutiv funksjon er avhengig av intakt arbeidsminne, som sørger for at data kan lagres og manipuleres under problemløsning, mens arbeidsminnet på sin side er underlagt eksekutiv kontroll (4). Enkelte definerer derfor arbeidsminnet som én av de eksekutive funksjonene (5).
Ragna Torgersen Engstad

Oslo universitetssykehus

Tora Torgersen Engstad

tora.engstad@me.com

Geriatrisk avdeling

Diakonhjemmet sykehus

\section{Svend Davanger}

Institutt for medisinske basalfag

Senter for molekylærbiologi og nevrovitenskap

Universitetet i Oslo

Torgeir Bruun Wyller

Universitetet i Oslo

og

Geriatrisk avdeling

Oslo universitetssykehus

Delt førsteforfatterskap mellom Ragna Torgersen Engstad og Tora Torgersen Engstad

Se også kunnskapsprøve

på www.tidsskriftet.no/quiz

Podkast på www.tidsskriftet.no

> Se også side 494

\section{HOVEDBUDSKAP}

Eksekutiv svikt etter hjerneslag medfører redusert evne til initiering, styring og monitorering av målrettet atferd og forblir ofte udiagnostisert

Eksekutiv svikt er fremtredende ved kognitiv svikt hos slagrammede

Tester for eksekutiv svikt bør brukes systematisk i slagenheter og poliklinikker

$\emptyset k t$ oppmerksomhet rundt eksekutiv svikt kan muligens bidra til bedret funksjon og høyere overlevelse etter hjerneslag 


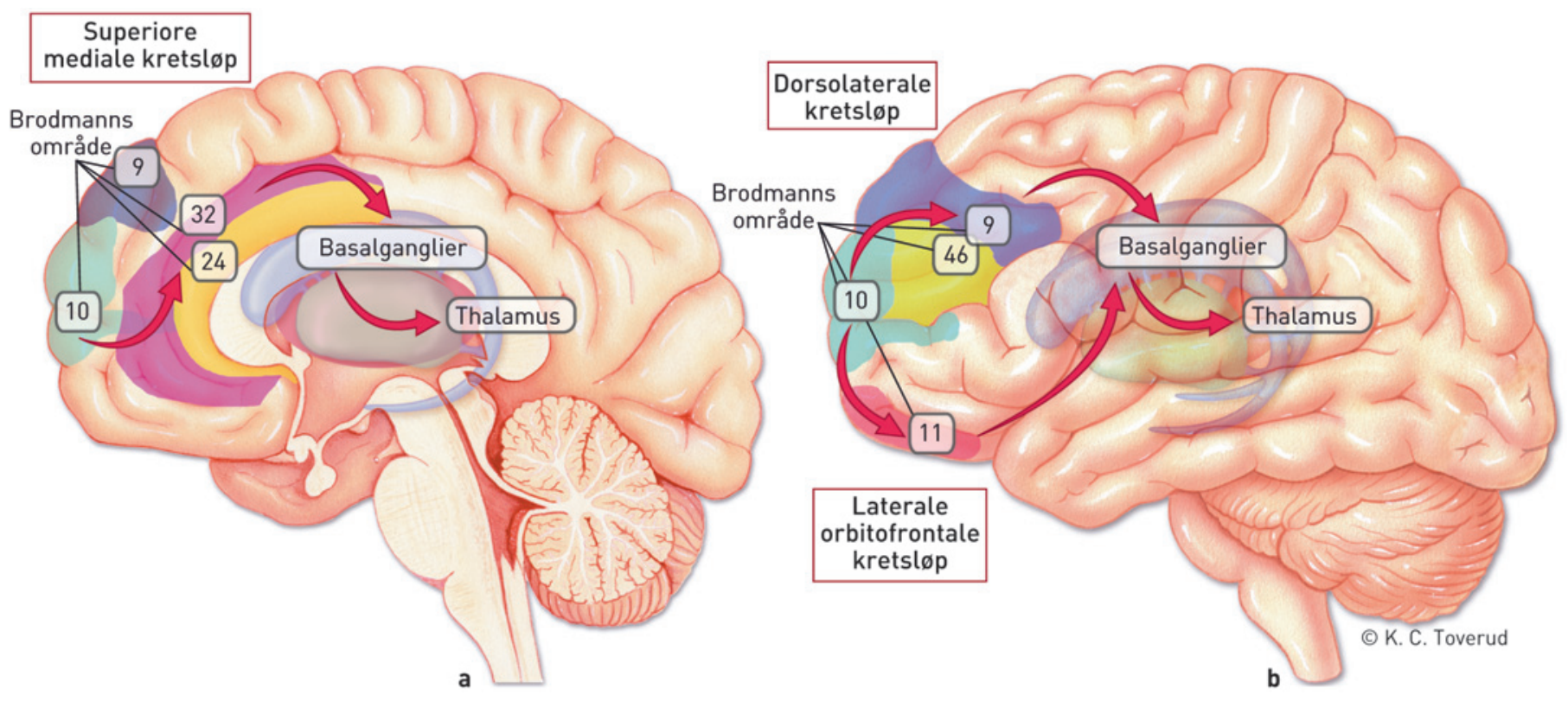

Figur 1 Nervebanene mellom frontallappene, basalgangliene og thalamus som er involvert i eksekutive funksjoner, kan deles i tre hovedgrupper: al den superiore mediale (atferdsmonitorering og atferdskorreksjon), b) den dorsolaterale (planlegging og arbeidsminne) og den laterale orbitofrontale (risikovurdering og hemming av upassende atferd) (1)

\section{Nevroanatomisk grunnlag og patofysiologi}

Prefrontal cortex og tilhørende subkortikale hjerneområder beskrives gjerne som hovedsetet for eksekutive funksjoner (3). Prefrontal cortex er området anteriort for motorisk cortex, dvs. Brodmanns område 8-13 og 44-47 (6). Denne delen av frontallappen mottar afferente fibre fra subkortikale hjerneområder, særlig den mediodorsale kjerne i thalamus, men har også tallrike fiberforbindelser med andre barkområder (fig 1). Prefrontal cortex modnes først i 20-30-årsalderen og er relativt større hos mennesket enn hos andre arter. Lenge var den etablerte oppfatning at eksekutive funksjoner var synonymt med frontale funksjoner (1), men skade på banene mellom prefrontal cortex og andre barkområder, som parietal- og oksipitallappen, kan også gi eksekutiv svikt (7). Sachdev og medarbeidere rapporterte i en MR-basert studie med 170 slagpasienter og matchede kontrollpersoner at kronisk iskemi i basalganglier og thalamus, ikke antall infarkter eller infarktvolum, viste sterkest sammenheng med eksekutiv dysfunksjon (8).

Ulike nevrodegenerative og psykiatriske lidelser kan også gi eksekutiv svikt. Felles for disse er at frontallappene eller frontosubkortikale baner ofte er affisert (3).

\section{Konsekvenser og relasjon til andre kognitive problemer}

Eksekutiv svikt etter hjerneslag påvirker mestringen av dagliglivets aktiviteter, blant annet via redusert evne til å ta avgjørelser, utøve dømmekraft og selvkorreksjon (9, 10). Balanse og mobilitet påvirkes av eksekutive evner som kognitiv fleksibilitet og responshemming. Mobilitetsvansker hos slagpasienter kan tilskrives kombinert motorisk og eksekutiv svikt (4). Redusert evne til initiering, sekvensering og vedlikehold av motoriske øvelser svekker potensialet for opptrening (11).

Depresjon og eksekutiv svikt sameksisterer ofte og kan gjøre at pasienten fremstår som langsom, med nedsatt visuell benevning, psykomotorisk retardasjon, tap av interesse for aktiviteter og eventuelt paranoide tanker (12). Denne sammenstillingen av symptomer har vært kalt «depression executive dysfunction syndrome», men begrepet er omstridt $(12,13)$.

Emosjonell instabilitet med ukontrollerte episoder med latter og/eller gråt er et sosialt hemmende symptom som ofte ses sammen med eksekutiv svikt. En mulig forklaring er at begge symptomer er assosiert med skade på frontale-subkortikale baner (14).

Apraksi kan forveksles med eksekutiv svikt, men begrepet har en annen nyanse. Mens eksekutiv svikt svekker evnen til planlegging og igangsetting av aktiviteter på et mer overordnet nivå, brukes apraksi om vansker med å gjennomføre en helt konkret motorisk handlingssekvens, som f.eks. å smøre brødskiven. Apraksi er feil valg av bevegelser og feil rekkefølge av disse (15), eksekutiv svikt rammer hele prosessen av ønsket aktivitet.

Nyere studier indikerer at utmattelse («fatigue») og apati er vanlige symptomer etter hjerneslag (16). Begge kan imitere eksekutiv svikt ved at de bidrar til nedsatt evne til igangsetting og gjennomføring av dagligdagse handlinger.

\section{Forekomst}

Prevalensen av eksekutiv svikt etter førstegangs hjerneslag varierer betydelig mellom ulike epidemiologiske studier $(5,17)$. Forekomsten er trolig høyest $\mathrm{i}$ akuttfasen, når trening og rehabilitering igangsettes (5). I en nederlandsk kohortstudie gjennomførte man nevropsykologisk kartlegging av 190 pasienter i akuttfasen av førstegangs hjerneslag. Eksekutiv svikt (39\%) og svekket visuell persepsjon/konstruksjon (38\%) var de to hyppigst forekommende kognitive symptomene.

I et norsk materiale av pasienter med rela- 
Tabell 1 Eksempler på tester for eksekutiv funksjon

$\begin{array}{ll}\text { Test } & \text { Utførelse } \\ \begin{array}{l}\text { Trail Making } \\ \text { Test B (TMT-B) }\end{array} & \begin{array}{l}\text { Pasienten får et ark med tall og bokstaver, og skal så fort som mulig } \\ \text { trekke en linje annenhver gang til tall og bokstav, begge i stigende } \\ \text { rekkefølge (1-A-2 - B osv.). Resultatet måles i sekunder }\end{array} \\ \begin{array}{l}\text { Verbal ordflyt-test } \\ \text { [«FAS-test») }\end{array} & \begin{array}{l}\text { Pasienten bes om å benevne så mange ord som mulig som begynner } \\ \text { på bokstavene F, A og S, unntatt egennavn, på en gitt tid }\end{array} \\ \text { Stroop-testen } & \begin{array}{l}\text { Pasienten skal så fort som mulig si fargen på et ord. Ordet er et farge- } \\ \text { navn, men en annen farge enn det ordet er trykt med (f.eks. ordet «rød» } \\ \text { skrevet med gule bokstaver) }\end{array} \\ & \text { Pasienten får utdelt kort som skal sorteres etter farge, type figurer eller } \\ \text { Wisconsin Card } & \text { antall figurer. For hvert kort som legges ut, får pasienten beskjed om det } \\ \text { Sorting Test } & \text { er lagt «riktig» eller «galt», men får ikke vite den underliggende regelen } \\ & - \text { som også endres underveis }\end{array}$

Funksjoner som evalueres

Evnen til å skifte mellom to kognitive set (mental fleksibilitet) og opprettholdelse av oppmerksomheten over tid

Evnen til å generere og variere responser, selvmonitorering av feil etter konkrete regler

Testen er følsom for mentalt tempo og for evnen til å undertrykke uønskede responser

Mental fleksibilitet, evne til å resonnere seg frem til riktig regel og til å skifte strategi tivt mildt førstegangs hjerneslag oppfylte nær halvparten av dem som var testbare i akuttfasen de predefinerte kriteriene for eksekutiv dysfunksjon (lav skåre på TrailMaking Test B) (Brynjar Fure, Seksjon for hjerneslag, Geriatrisk avdeling, Oslo universitetssykehus, upubliserte data).

Ettersom eksekutiv svikt har vært assosiert med subkortikale skader, har man knyttet symptombildet til lakunære hjerneslag. I henhold til TOAST-kriteriene (Trial of Org 10172 in Acute Stroke Treatment), den vanligst brukte patofysiologiske inndelingen av hjerneslag, skyldes slike slag småkarssykdom i hjernen (18). Hos pasienter med kortikale slag kan eksekutive vansker også være til stede, slik innledningseksemplet illustrerer, men det er sannsynlig at de ofte overskygges av mer iøynefallende symptomer som vanskeliggjør bruk av vanlige tester for eksekutiv funksjon.

Eksekutiv svikt forekommer også etter traumatiske hjerneskader og ved lidelser som depresjon, schizofreni, hyperkinetiske forstyrrelser (AD/HD), tvangslidelser, alkoholisme, hjernesvulster, Parkinsons sykdom og multippel sklerose. Av demenssykdommene er det lewylegemedemens, demens ved Parkinsons sykdom og frontotemporallappsdemens som er sterkest assosiert med eksekutiv svikt, men symptomet er også vanlig ved Alzheimers sykdom (3, 19, 20). Normal aldring er relatert til moderat svekket eksekutiv funksjon (21).

\section{Prognose}

Utviklingen av eksekutiv svikt etter hjerneslag er lite undersøkt, men klinisk erfaring tilsier at symptomene gjerne bedres gradvis i løpet av 3-6 måneder. Mange har likevel vedvarende plager.

Eksekutiv svikt er assosiert med nedsatt overlevelse (12). En finsk forskergruppe fulgte en kohort av 257 hjerneslagpasienter over en 12-årsperiode og undersøkte om depresjon og eksekutiv svikt hadde noen effekt på overlevelsen (12). De fant statistisk signifikant lavere overlevelse blant dem med eksekutiv svikt sammenliknet med de øvrige, henholdsvis 6,4 år og 10,6 år. Depresjon alene påvirket imidlertid ikke overlevelsen.

\section{Diagnostikk}

\section{Anamnese}

Innhenting av detaljerte komparentopplysninger om pasienten før og etter slaget er viktig for kartlegging av eksekutiv svikt. Har vedkommende vansker med praktiske gjøremål eller problemer med å komme i gang? Blir pasienten lettere distrahert enn før?

\section{Tester på eksekutiv funksjon}

Kognitive evner etter et hjerneslag kan fluktuere, og tester gir kun et øyeblikksbilde. Gjentatte undersøkelser kan være nødvendig (22). Globale kognitive tester, som Mini Mental Status Evaluering (MMSE), er dårlig egnet til kartlegging av eksekutiv svikt $(4,23)$.

Tabell 1 gir eksempler på tester som kan gi informasjon om eksekutiv funksjon. Trail Making Test B og Verbal ordflyt-test er mest brukt og tar under fem minutter (20), men testprestasjonene kan også påvirkes av annen kognitiv svikt. Pasienter med eksekutiv svikt som eneste kognitive symptom vil ofte gjøre det bra på de vanlige kognitive testene der det gis en klar instruksjon og rammene er definert av legen. Problemene kommer først frem i testsituasjoner der pasienten selv må gjøre valg eller ta initiativ (24).

Enkelttester vil ikke kartlegge eksekutive funksjoner utfyllende (25), men bør brukes systematisk som screening ved kognitiv utredning. Observasjon i dagliglivets komplekse oppgaver som matlaging, bruk av telefon, betaling av regninger og administrering av legemidler kan gjennomføres av en øvet ergoterapeut og gir informasjon om både eksekutiv funksjon og hjelpebehov (9).

\section{Behandling}

\section{Informasjon}

God informasjon om eksekutiv svikt og konsekvensene av tilstanden til pasient og pårørende kan forhindre at pasientens endrede atferd fører til selvbebreidelser og bebrei- delser fra omgivelsene og kan i noen grad redusere den psykososiale belastningen. Kunnskap gjør det mulig for pasienten og menneskene rundt å utarbeide kompenserende mestringsstrategier.

\section{Fysisk aktivitet og livsstil}

Fysisk aktivitet kan sannsynligvis i noen grad forebygge og reversere eksekutiv svikt $(26,27)$, dessuten bedre hukommelse og psykomotorisk tempo (22). Mulige forklaringer er bedret cerebral perfusjon, hemming av inflammatoriske mediatorer og/eller nedsatt utskilling av stresshormoner (20) samt økt produksjon av nervevekstfaktorer. Eksekutiv svikt etter hjerneslag er en prediktor for lav fysisk aktivitet, og strategier for økt aktivitetsnivå kan være til hjelp (27).

\section{Rehabilitering}

Eksekutiv svikt vanskeliggjør strukturert og målrettet rehabilitering etter slag, inkludert innlæring av kompensatoriske teknikker som å klare praktiske oppgaver med én hånd. Man må derfor ta hensyn til dette ved planlegging av motorisk rehabilitering (5).

\section{Kognitiv rehabilitering}

Gjennom systematisk opptrening med vekt på de områder der pasienten har problemer kan kognitiv rehabilitering gi bedret funksjon etter hjerneslag (28). Dette kan gjøres gjennom gjentatte øvelser eller utvikling av kompenserende strategier. I en metaanalyse anbefales standardiserte strategier for problemløsning, stopp i løpet av oppgaven for bevisst selvmonitorering eller bruk av for eksempel videofeedback. (28). Potensialet for gjenvinning av eksekutiv funksjon er ukjent, men slike metoder vil trolig kunne fremme rehabilitering også av andre kognitive funksjoner.

\section{Legemidler}

Sekundærprofylakse mot hjerneslag med vekt på tradisjonelle risikofaktorer som høyt blodtrykk, kolesterolnivå, atrieflimmer, diabetes mellitus, koronar hjertesykdom og komorbide 
tilstander antas å forebygge videre progrediering av kognitiv svikt (29).

En studie fra 2003 indikerer at antidepressiver kan bedre funksjonen etter hjerneslag, også hos dem som ikke fyller de kliniske kriteriene for depresjon (30). En slik effekt kan muligens relateres til antidepressive midlers virkning på frontale kortikale-subkortikale baner, men også effekten på nevrogenese og reorganisering av nevronale nettverk (31).

\section{Diskusjon}

Eksekutiv svikt er assosiert med redusert overlevelse, men mekanismen bak dette er ukjent. Kanskje er det i realiteten den generaliserte karsykdommen som er den bakenforliggende årsak til tidlig død (32). Oksala og medarbeidere fant at over halvparten av dem med akutt hjerneslag hadde alvorlig småkarssykdom med forandringer $\mathrm{i}$ hvit substans - dette var en uavhengig prediktor for tidlig død (33) En alternativ forklaring er at eksekutiv svikt påvirker dødsrisikoen gjennom redusert funksjon i dagliglivet, mindre effektiv behandling og rehabilitering og økt risiko for traumer (12).

Eksekutiv svikt ses også hos pasienter med bildediagnostiske tegn på kronisk iskemi i hvit substans uten manifeste hjerneslag (34, 35) Det frontale subkortikale ledningsnettet er svært sårbart for sirkulasjonsforstyrrelser som hypoperfusjon (20). Kanskje er det slik at eksekutiv svikt forekommer som et kontinuum ved øvrig subklinisk cerebrovaskulær sykdom, med akutt forverring ved manifeste hjerneslag $(5,36)$.

Hjerneslag gir sammensatt funksjonssvikt. Systematisk observasjon i hverdagssituasjoner, gjennomført av fagfolk i en strukturert setting, er kanskje det nærmeste man kommer en gullstandard for diagnostikk. Dette er tidkrevende i en klinisk hverdag, og standardisering er vanskelig. Tverrfaglig samarbeid kan være nøkkelen til å avdekke omfanget av eksekutiv svikt (9).

Det er fortsatt mye vi ikke vet om eksekutiv svikt etter hjerneslag. I nye studier bør man kombinere klinisk erfaring og ny kunnskap om nevroanatomi og patofysiologi. En dypere forståelse av eksekutiv svikt kan gi bedre diagnostikk og behandling.

Vi takker Torgeir Engstad og Brynjar Fure for gode innspill

\section{Ragna Torgersen Engstad (f. 1978)}

er turnuslege.

Forfatter har fylt ut ICMJE-skjemaet og oppgir ingen interessekonflikter.

\section{Tora Torgersen Engstad (f. 1981)}

er lege i spesialisering

Forfatter har fylt ut ICMJE-skjemaet og oppgir ingen interessekonflikter.

\section{Svend Davanger (f. 1958)}

er professor i anatomi ved Universitetet i Oslo. Forfatter har fylt ut ICMJE-skjemaet og oppgir ingen interessekonflikter.

\section{Torgeir Bruun Wyller (f. 1960)}

er professor i geriatri ved Oslo universitetssykehus.

Forfatter har fylt ut ICMJE-skjemaet og oppgir ingen interessekonflikter.

\section{Litteratur}

1. Stuss DT. Functions of the frontal lobes: relation to executive functions. J Int Neuropsychol Soc 2011; 17: 759-65

2. Jurado MB, Rosselli M. The elusive nature of executive functions: a review of our current understanding. Neuropsychol Rev 2007: 17: 213-33.

3. Elliott R. Executive functions and their disorders. Br Med Bull 2003; 65: 49-59.

4. Liu-Ambrose T, Pang MY, Eng JJ. Executive function is independently associated with performances of balance and mobility in community-dwelling older adults after mild stroke: implications for falls prevention. Cerebrovasc Dis 2007; 23: 203-10.

5. Zinn S, Bosworth HB, Hoenig HM et al. Executive function deficits in acute stroke. Arch Phys Med Rehabil 2007; 88: 173-80.

6. Fuster JM. The prefrontal cortex. 4. utg. London: Academic press, 2008

7. Smith EE, Salat DH, Jeng J et al. Correlations between MRI white matter lesion location and executive function and episodic memory. Neurology 2011; 76: 1492-9.

8. Sachdev PS, Brodaty H, Valenzuela MJ et al. The neuropsychological profile of vascular cognitive impairment in stroke and TIA patients. Neurology 2004; 62: 912-9.

9. Baum CM, Connor LT, Morrison T et al. Reliability validity, and clinical utility of the Executive Function Performance Test: a measure of executive function in a sample of people with stroke. Am J Occup Ther 2008; 62: 446-55

10. Engstad T, Viitanen M, Almkvist O. Kognitiv svikt etter hjerneslag - diagnostikk og håndtering. Tidsskr Nor Lægeforen 2007: 127: 1390-3.

11. Mok VC, Wong A, Lam WW et al. Cognitive impair ment and functional outcome after stroke associated with small vessel disease. J Neurol Neurosurg Psychiatry 2004: 75: 560-6.

12. Melkas S, Vataja R, Oksala NK et al. Depressionexecutive dysfunction syndrome relates to poor poststroke survival. Am J Geriatr Psychiatry 2010; 18: 1007-16.

13. McLennan SN, Mathias JL. The depression-executive dysfunction (DED) syndrome and response to antidepressants: a meta-analytic review. Int $J$ Geriatr Psychiatry 2010; 25: 933-44.

14. Tang WK, Chen Y, Lam WW et al. Emotional incontinence and executive function in ischemic stroke: a case-controlled study. J Int Neuropsychol Soc 2009; 15: 62-8

15. Wyller TB, Sveen U. Ikke-språklige kognitive symptomer etter hjerneslag. Tidsskr Nor Lægeforen 2002; 122: 627-30.

16. Winward C, Sackley C, Metha Z et al. A population based study of the prevalence of fatigue after transient ischemic attack and minor stroke. Stroke 2009: 40: 757-61.

17. Riepe MW, Riss S, Bittner D et al. Screening for cognitive impairment in patients with acute stroke. Dement Geriatr Cogn Disord 2004; 17: 49-53.

18. Adams HP jr., Bendixen BH, Kappelle LJ et al. Classification of subtype of acute ischemic stroke. Definitions for use in a multicenter clinical trial. TOAST. Trial of Org 10172 in Acute Stroke Treatment. Stroke 1993; 24: 35-41.

19. Tekin S, Cummings JL. Frontal-subcortical neuronal circuits and clinical neuropsychiatry: an update. J Psychosom Res 2002; 53: 647-54.
20. Schillerstrom JE Horton MS, Royall DR The impact of medical illness on executive function. Psychosomatics 2005; 46: 508-16

21. Leskelä M, Hietanen M, Kalska $\mathrm{H}$ et al. Executive functions and speed of mental processing in elderly patients with frontal or nonfrontal ischemic stroke. Eur J Neurol 1999; 6: 653-61

22. McDonnell MN, Bryan J, Smith AE et al. Assessing cognitive impairment following stroke. J Clin Exp Neuropsychol 2011; 33: 945-53.

23. Engstad T, Almkvist O, Viitanen M et al. Impaired motor speed, visuospatial episodic memory and verbal fluency characterize cognition in long-term stroke survivors: the Troms $\varnothing$ Study. Neuroepidemiology 2003; 22: 326-31.

24. Ownsworth T, Shum D. Relationship between executive functions and productivity outcomes following stroke. Disabil Rehabil 2008; 30: 531-40.

25. Miyake A, Emerson MJ, Friedman NP. Assessment of executive functions in clinical settings: problems and recommendations. Semin Speech Lang 2000; $21: 169-83$

26. Rand D, Eng JJ, Liu-Ambrose T et al. Feasibility of a 6-month exercise and recreation program to improve executive functioning and memory in ind viduals with chronic stroke. Neurorehabil Neural Repair 2010; 24: 722-9.

27. Påhlman U, Sävborg M, Tarkowski E. Cognitive dysfunction and physical activity after stroke: the Gothenburg cognitive stroke study in the elderly. J Stroke Cerebrovasc Dis 2012; 21: 652-8.

28. Cicerone KD, Langenbahn DM, Braden $\mathrm{C}$ et al. Evidence-based cognitive rehabilitation: updated review of the literature from 2003 through 2008. Arch Phys Med Rehabil 2011; 92: 519-30.

29. Gorelick PB, Scuteri A, Black SE et al. Vascular contributions to cognitive impairment and dementia: a statement for healthcare professionals from the american heart association/american stroke association. Stroke 2011; 42: 2672-713

30. Jorge RE, Robinson RG, Arndt S et al. Mortality and poststroke depression: a placebo-controlled trial of antidepressants. Am J Psychiatry 2003; 160: $1823-9$

31. Narushima K, Paradiso S, Moser DJ et al. Effect of antidepressant therapy on executive function after stroke. Br J Psychiatry 2007: 190: 260 -5.

32. Brookes RL, Hannesdottir K, Lawrence R et al. Brief Memory and Executive Test: evaluation of a new screening test for cognitive impairment due to small vessel disease. Age Ageing 2012 41: $212-8$

33. Oksala NK, Oksala A, Pohjasvaara T et al. Age related white matter changes predict stroke death in long term follow-up. J Neurol Neurosurg Psychiatry 2009: 80: 762-6.

34. Prins ND, van Dijk EJ, den Heijer T et al. Cerebral small-vessel disease and decline in information processing speed, executive function and memory. Brain 2005: 128: 2034-41

35. Ihle-Hansen $\mathrm{H}$, Thommessen B, Fagerland MW et al. Impact of white matter lesions on cognition in stroke patients free from pre-stroke cognitive impairment: a one-year follow-up study. Dement Geriatr Cogn Dis Extra 2012: 2: 38-47.

36. Amberla K, Wäljas M, Tuominen $\mathrm{S}$ et al. Insidious cognitive decline in CADASIL. Stroke 2004; 35 1598-602.

Mottatt 11.6. 2012, første revisjon innsendt 13.10 . 2012, godkjent 20.12. 2012. Medisinsk redaktør Merete Kile Holtermann. 